\title{
Physical activation of graphene: An effective, simple and clean procedure for obtaining microporous graphene for high- performance Li/S batteries
}

Almudena Benítez ${ }^{1}$, Alvaro Caballero ${ }^{1}$, Julián Morales ${ }^{1}(\varangle)$, Jusef Hassoun ${ }^{2}(\bowtie)$, Enrique Rodríguez-Castellón ${ }^{3}$, and Jesús Canales-Vázquez ${ }^{4}$

${ }^{1}$ Dpto. Química Inorgánica e Ingeniería Química, Instituto de Química Fina y Nanoquímica, Universidad de Córdoba, 14071 Córdoba, Spain

${ }^{2}$ Department of Chemical and Pharmaceutical Sciences, University of Ferrara, Via Fossato di Mortara, 17, 44121, Ferrara, Italy

${ }^{3}$ Dpto. de Química Inorgánica, Cristalografía y Mineralogía, Facultad de Ciencias, Universidad de Málaga, 29071 Málaga, Spain

${ }^{4}$ Instituto de Energías Renovables, Universidad de Castilla-La Mancha, Paseo de La Investigación 1, Albacete, 02071, Spain

(C) Tsinghua University Press and Springer-Verlag GmbH Germany, part of Springer Nature 2019

Received: 28 September 2018 / Revised: 10 December 2018 / Accepted: 28 December 2018

Address correspondence to Julián Morales, iq1mopaj@uco.es; Jusef Hassoun, jusef.hassoun@unife.it 


\begin{abstract}
Graphene nanosheets are a promising scaffold to accommodate $\mathrm{S}$ for achieving high performance Li/S battery. Nanosheet activation is used as a viable strategy to induce a micropore system and further improve the battery performance. Accordingly, chemical activation methods dominate despite the need of multiple stages, which slow down the process in addition to making them tiresome. Here, a three-dimensional (3D) N-doped graphene specimen was physically activated with $\mathrm{CO}_{2}$, a clean and single step process, and used for the preparation of a sulfur composite (A-3DNG/S). The A-3DNG/S composite exhibited outstanding electrochemical properties such as an excellent rate capability $\left(1,000 \mathrm{mAh} \cdot \mathrm{g}^{-1}\right.$ at $\left.2 \mathrm{C}\right)$, high reversible capacity and cycling stability (average capacity $\sim 800 \mathrm{mAh} \cdot \mathrm{g}^{-1}$ at $1 \mathrm{C}$ after 200 cycles), values which exceed those measured in chemically activated graphene. Therefore, these results support the use of physical activation as a simple and efficient alternative to improve the performance of carbons as an S host for high-performance Li-S batteries.
\end{abstract}

\title{
Keywords
}

physical activation, 3D-graphene, solvothermal microwave synthesis, Li-S battery 


\section{Introduction}

Currently, there is a wide variety of commercial batteries in the market. One of the most promising types is the Li-ion battery (LIB), which is the system currently used in portable electronic devices. There is a great interest in the development of high energy and power density systems to achieve progress in hybrid or fully electric vehicles as well as in renewable energies. For these applications, Li-ion batteries present serious shortcomings, which is mainly a result of inherently limited energy being supplied to the chemical intercalation processes which drives the electrochemical reaction $[1,2]$. Other reversible electrochemical reactions such as the conversion process between Li and $\mathrm{S}$, with a theoretical specific energy of $2,600 \mathrm{Ah} \cdot \mathrm{kg}^{-1}$, may actually double the practical energy with respect to commercial LIBs [3-6]. Nevertheless, Li-S batteries present drawbacks including: (i) low conductivity due to the insulating nature of sulphur; (ii) structural changes of the materials and volume variations during the electrochemical process; (iii) formation of soluble polysulphides in the electrolyte which may unlikely shuttle between anode and cathode; (iv) possible deposition of insoluble polysulphides on the lithium surface. All these issues may lead to active material loss at the cathode, and decrease of the cell performance in terms of efficiency and reversible capacity values [3].

To address these challenges, various conducting matrices have been developed to host sulphur and avoid the dissolution of the active material, including micro/mesoporous carbon [7-12], carbon nanotubes [13, 14], graphitic oxide [15, 16], and graphene sheets [17-20]. Particularly, graphene represents an excellent candidate due to its relevant theoretical surface area of $2,675 \mathrm{~m}^{2} \cdot \mathrm{g}^{-1}$ [21] and high electrical conductivity allowing fast electron mobility $\left(\geq 15,000 \mathrm{~cm}^{2} \cdot \mathrm{V}^{-1} \cdot \mathrm{s}^{-1}\right)$ [22]. However, the practical value of the 
surface area is generally lower due to the tendency of this material to agglomerate through strong $\pi$-stacking [23].

Indeed, three-dimensional (3D) cross-linked network structure represents a good alternative to avoid the rearrangement of the graphene sheets and to generate meso/macropores, thus improving the electrode wettability by the electrolyte solution [24]. 3D graphene has been studied in previous work $[25,26]$, which have proven that the electrochemical properties may be actually improved by structural modification of this important host. Furthermore, doping graphene with heteroatoms (S, N, B and P) [27-29], particularly nitrogen [30-40], creates electrochemically active sites and promotes a strong interaction between lithium and the heteroatoms, thus enabling fast charge transfer and limited polysulfides dissolution in the electrolyte. Further property suitable for improving the $\mathrm{Li} / \mathrm{S}$ cell behaviour is the presence of micropores within the system which enhance the polysulphide absorption and mitigate the shuttle effect. This important characteristic may be achieved by activating the carbons either using physical or chemical methods. The chemical activation employs different agents [41], including phosphoric acid, zinc chloride, and potassium hydroxide. Although these agents offer advantages such as a severe surface attack that results in enhanced porosity, the chemical process may be slow and tiresome as it requires multiple steps until the achievement of the clean and dried material. Instead, physical activation is a one-step process, which requires oxidizing gases such as carbon dioxide or other steam; therefore, this process can be cleaner, simpler and faster compared to the chemical activation [42]. Chemical methods have been used to carry out graphene activation to induce microporosity for improving its action in Li-S with promising results [43-48], while physically activated graphene demonstrated better performances than that chemically activated in adsorption and catalytic processes [49]. However, to the best of 
our knowledge, there are no reports on physically activated graphene operating in Li-S batteries.

Herein, a porous physically activated 3D N-doped graphene is used as the $\mathrm{S}$ host for $\mathrm{Li} / \mathrm{S}$ battery. The carbon host is synthesized by using a microwave furnace to exfoliate graphitic oxide (GO) in the presence of urea as the $\mathrm{N}$ source and subjected to further activation with $\mathrm{CO}_{2}$. The obtained multi-interconnected channel framework of micro-, meso- and macropores supported the sulphur composite, and was able to enhance both the electrode impregnation by the electrolyte and the ability to trap polysulphides during the electrochemical process. These beneficial properties are reflected into an excellent performance of the Li/S battery which exceeds that reported in the literature for cells using chemically activated graphene.

\section{Experimental section}

\subsection{Synthesis of activated 3D N-doped graphene (A-3DNG)}

An activated 3D N-doped graphene was prepared from pristine graphite flakes, which were oxidized to GO using the modified Hummers method described in a previous work [50]. The 3D N-doped graphene matrix was synthesized with a microwave-assisted solvothermal technique. Urea was employed as a source of nitrogen and as a reducing agent for GO during the hydrothermal assembly process. In a typical procedure, an aqueous suspension of $\mathrm{GO}\left(40 \mathrm{~mL}, 2 \mathrm{mg} \cdot \mathrm{mL}^{-1}\right)$ was dispersed through ultrasonication for $1 \mathrm{~h}$ and then added with $370 \mathrm{mg}$ urea. The suspension was transferred into a $100 \mathrm{~mL}$ Teflon-lined autoclave and put into a microwave oven (Milestone flexiWAVE) at a power of $350 \mathrm{~W}$ and temperature of $200{ }^{\circ} \mathrm{C}$ for $12 \mathrm{~h}$. Then, the hydrogel was washed with distilled water and the wet hydrogel was freeze-dried (Telstar Lyo Quest, Mod. 85) to obtain the 3D N-doped graphene (3DNG) monolithic sponge [51]. Finally, the 3D N- 
doped graphene was activated by a thermal treatment in a tubular oven at $900{ }^{\circ} \mathrm{C}$ for $3 \mathrm{~h}$ with a ramp rate of $5^{\circ} \mathrm{C} \cdot \mathrm{min}^{-1}$ using a flow of carbon dioxide $\left(50 \mathrm{~mL} \cdot \mathrm{min}^{-1}\right)$; this sample is indicated by the acronym A-3DNG. The synthesis pathway of the a-3DNG from graphitic oxide is schematically described in Fig. 1.

\subsection{Synthesis of A-3DNG/S composite and electrode preparation}

Sulphur impregnation was carried out by the method described by literature [52]. 200 $\mathrm{mg}$ of sublimed sulphur (VWR Chemical) was dissolved in $10 \mathrm{~mL}$ ethylenediamine (Sigma Aldrich) and added drop by drop onto an aqueous solution with $100 \mathrm{~mL}$ deionized water, $10 \mathrm{~mL}$ of dry absolute ethanol (Panreac), and the activated 3D Ndoped graphene previously dispersed in an ultrasonic bath for $30 \mathrm{~min}$ to obtain the A3DNG-S composite, which will be used as cathodic material.

The electrode was prepared by mixing $80 \mathrm{wt} . \%$ composite, $10 \mathrm{wt} . \%$ conducting agent (Super P carbon, Timcal) and 10 wt.\% binder of polyvinylidene difluoride (PVDF, Solvay) in N-methyl-2-pyrrolidone (NMP, Sigma Aldrich) to form the slurry. Subsequently, the slurry was pasted onto a carbon paper (GDL, ELAT LT1400W) and dried for $3 \mathrm{~h}$ at $50{ }^{\circ} \mathrm{C}$. The dry electrode was cut into disks of $13-\mathrm{mm}$ diameter and the active material loading was between $1.2-2.0 \mathrm{mg} \cdot \mathrm{cm}^{-2}$.

\subsection{Characterization techniques}

X-ray photoelectron spectroscopy (XPS) measurements were carried out with a Physical Electronics PHI 5700 spectrometer using monochromatic $\mathrm{Mg} \mathrm{K \alpha}$ radiation and a multichannel detector. X-ray diffraction patterns (XRD) were obtained with a Bruker D8 Discover X-ray diffractometer using monochromatic $\mathrm{Cu} \mathrm{K} \alpha$ radiation. The patterns were recorded within the $5^{\circ}-80^{\circ}(2 \theta)$ range, using a step size of $0.040^{\circ}$ and $1.05 \mathrm{~s}$ per step. The Raman spectra were recorded under ambient conditions using a Renishaw in 
Via Microscope equipped with a detector Renishaw CCD Camera $(578 \times 400)$ and a laser of $532 \mathrm{~nm}$ edge in line focus mode. The ultraviolet/visible (UV/vis) spectra were recorded with a Spectronic Gamma Helios instrument in a wavelength range of 300$550 \mathrm{~nm}$. The nitrogen adsorption/desorption data were obtained at the liquid nitrogen temperature $(77 \mathrm{~K})$ using a Micromeritics ASAP $2020 \mathrm{M}$ apparatus. The samples were degassed at $150{ }^{\circ} \mathrm{C}$ under vacuum for $6 \mathrm{~h}$ prior to the measurement. Pore size distribution was calculated by the density functional theory (DFT) method applied to the adsorption branch of the isotherm. The total pore volumes were calculated from the amount adsorbed at a relative pressure $\left(P / P_{0}\right)$ of 0.99 and micropore volume by the Dubinin-Raduskevich method [53]. The specific surface area was calculated using the Brunauer-Emmett-Teller (BET) equation. Thermogravimetric measurements were made using a Mettler Toledo-TGA/DSC under nitrogen atmosphere by heating the sample from 25 to $600{ }^{\circ} \mathrm{C}$ at $5^{\circ} \mathrm{C} \cdot \mathrm{min}^{-1}$. Sample morphology was investigated with a JEOL JSM-7800F scanning electron microscope (SEM) and transmission electron microscopy (TEM) images were obtained with a JEOL 2100 electron microscope operating at $200 \mathrm{kV}$ and equipped with an Orius Gatan CCD camera.

\subsection{Electrochemical measurements}

Electrochemical experiments were performed on CR2032 coin-type test cells assembled in an argon-filled glovebox (M-Braun 150 model) with lithium metal as the counter and reference electrodes at room temperature. The electrolyte was 1 mol LiTFSI (Sigma Aldrich), and 1 mol $\mathrm{LiNO}_{3}$ (Sigma Aldrich) in $1 \mathrm{~kg}$ of a 1:1 (w:w) mixture of 1,3dioxolane (DOL, Sigma Aldrich) and 1,2-dimethoxyethane (DME, Sigma Aldrich) impregnated in a polyethylene membrane (Celgard) as the separator. Cyclic voltammetry $(\mathrm{CV})$ measurements were performed at a scan rate of $0.1 \mathrm{mV} \cdot \mathrm{s}^{-1}$ by using 
a Solartron 1470 battery tester. CV tests were carried out within the 1.9-2.7 V range. Electrochemical impedance spectroscopy (EIS) was recorded on an Autolab equipment in the frequency range of $500 \mathrm{kHz}$ to $0.1 \mathrm{~Hz}$ at a disturbance amplitude of $10 \mathrm{mV}$. The analysis of the EIS data was carried out by means of FRA 4.9 software. Galvanostatic cycling measurements were conducted in a voltage range of $2.6-1.8 \mathrm{~V}$ on an Arbin BT2143 potentiostat-galvanostat system. The specific capacity values were calculated based on the sulphur loading in the electrode.

\section{Results and discussion}

The structural properties of activated $\mathrm{N}$-doped graphene were examined by XRD, Raman spectroscopy, and XPS. The XRD pattern is shown in Fig. S1(a) (top pattern) in the Electronic Supplementary Material (ESM). The pattern shows the typical shape expected for chemically prepared graphene, indicating highly disordered graphite [54] with a strong and wide peak at ca. $26.5^{\circ} 2 \theta$ assigned to the (002) plane with a spacing of $3.54 \AA$, that is, a notably higher value than pristine graphite $(3.38 \AA)$. Furthermore, the pattern reveals a wide and less intense peak at ca. $43.5^{\circ} 2 \theta$, where different (101) planes appear with similar spacing being the more intense peak. The pattern of pristine activated $\mathrm{N}$-doped graphene (not reported here) indicates that $\mathrm{CO}_{2}$ treatment hardly lefts a trace detectable by XRD diffraction. After S impregnation, the characteristic peaks of orthorhombic sulphur are clearly detected in the composite (Fig. S1(a), bottom curve, in the ESM). The Raman spectrum of graphene (Fig. S1(b) in the ESM) displays two wellknown peaks at 1,345 and $1,591 \mathrm{~cm}^{-1}$; these are assigned to $\mathrm{D}$ and $\mathrm{G}$ bands due to the vibration of defects and of the $\mathrm{C}-\mathrm{C}$ bonds in the carbon framework, respectively. It is worth mentioning that the $I_{\mathrm{D}} / I_{\mathrm{G}}$ ratio shows a value of 1.06 both for A-3DNG and for 3DNG (Spectrum not reported), thus suggesting minor influence of the $\mathrm{CO}_{2}$ treatment 
on the disorder degree $[55,56]$. Thermogravimetric (TG) analysis was used to determine the content in the A-3DNG/S composite (Fig. S2 in the ESM). The curve shows a weight loss above $150{ }^{\circ} \mathrm{C}$ due to $\mathrm{S}$ sublimation and one peak in the corresponding differential curve, thus indicating a single-step process with a $\mathrm{S}$ to $\mathrm{C}$ weight ratio of $70 \%$.

The survey XPS scan of A-3DNG shown in Fig. S3 reveals three elements as the main components at the level surface, that is, $\mathrm{C}, \mathrm{O}$ and $\mathrm{N}$, the content of which is exhibited in Table 1. The C 1s spectrum was fitted to six components (Fig. 2(a)) [57-59], whose contributions and their binding energies are shown in Table 2. The main contribution is due $-\mathrm{C}-\mathrm{C}-$ and $-\mathrm{C}=\mathrm{C}-$ and adventitious carbon. The second contribution was assigned to $\mathrm{C}-\mathrm{N}$ bonds, mainly from pyridinic and pyrrolic compounds [48]. The low relative intensity contributions at higher binding energies were assigned to $\mathrm{C}-\mathrm{O}, \mathrm{C}=\mathrm{O}, \mathrm{O}-\mathrm{C}=\mathrm{O}$ groups at $286.7,288.0$ and $289.0 \mathrm{eV}$, respectively, and that at $290.8 \mathrm{eV}$ to a satellite peak due to $\pi \rightarrow \pi^{*}$ transition. More useful information on $\mathrm{N}$ is obtained from its $1 \mathrm{~s}$ photoemission spectrum, which is fitted to three components corresponding to pyridinic, pyrrolic and graphitic nitrogen (Fig. 2(b)). Their contributions to the spectrum are reported in Table 3 which reveals that the $\mathrm{CO}_{2}$ activation process decreases the $\mathrm{N}$ content of A-3DNG compared to 3DNG, and affects the relative contributions of the three chemical environments with increase of the graphitic $\mathrm{N}$ component with respect to the pyrrolic $\mathrm{N}$ component $[56,57]$.

The surface area and pore structure of the graphene-based sulphur electrode play a significant role in its electrochemical behaviour in Li-cell. These properties were determined from $\mathrm{N}_{2}$ adsorption measurements. The adsorption/desorption isotherm of A-3DNG as well as that of A-3DNG /S composite are shown in Fig. 3. At low pressure $\left(P / P_{\mathrm{o}} \sim 0.2\right)$, the A-3DNG isotherm shape is better fitted to type $\mathrm{I}$ in BDDT 
classification, which is typical of micropore solids. It is worth mentioning that the IVtype shape, typical of monolayer-multilayer, and capillary condensation generally revealed by the hysteresis loop, is the shape adopted by pristine graphene [56]. Therefore, the activation with $\mathrm{CO}_{2}$ causes a significant increase in both the BET surface area and pore volume. The former changes from 261 to $432 \mathrm{~m}^{2} \cdot \mathrm{g}^{-1}$ and the pore volume from 0.29 to $0.53 \mathrm{~cm}^{3} \cdot \mathrm{g}^{-1}$ [56]. Micropore volume obtained from the DubininRadushkevich model [53] is $0.17 \mathrm{~cm}^{3} \cdot \mathrm{g}^{-1}$; this is more than $30 \%$ of the total pore volume. The pore size distribution analysed by the DFT model is shown in Fig. S4 in the ESM. The figure reveals that the pore size distribution ranges from 1 to $10 \mathrm{~nm}$ and confirms the micro and mesoporous properties of the synthesized graphene. After $\mathrm{S}$ impregnation, the isotherm shape changes to type II, a classification that is typical of non-porous solids (see inset of Fig. 3). As expected, both the surface area and pore volume undergo a drastic decrease of $6 \mathrm{~m}^{2} \cdot \mathrm{g}^{-1}$ and $0.05 \mathrm{~cm}^{3} \cdot \mathrm{g}^{-1}$, respectively.

The morphology of the $\mathrm{CO}_{2}$-activated graphene was evaluated by SEM and TEM. The SEM image of Fig. 4(a) reveals a 3D network of randomly oriented, wrinkled graphene sheets evidenced by TEM image in Fig. 4(b). This structure is due to the exfoliation and assembly processes undergone by the GO flakes during the microwave treatment. The activation hardly affected the external sheet morphology; indeed, the microscopy indicates that the carbonaceous skeleton is slightly more ordered compared to the pristine 3DNG previously studied [56]. Furthermore, the A-3DNG reveals more extended regions with fringes of ca. $0.34 \mathrm{~nm}$, assigned to (002) crystallographic planes of graphite, with respect to the pristine 3DNG (Fig. S5 in the ESM). The higher graphitization degree is caused by the $\mathrm{CO}_{2}$-activation, which is in line with the increase of graphitic N content as revealed by XPS data (see Table 3). Upon S-impregnation, the graphene sheets maintain their corrugated morphology as revealed by TEM in Figs. 5(a) 
and 5(b). The images with increased in Fig. 5(c) clearly show the nanometric S particles with size below $10 \mathrm{~nm}$ consistently with the experimental conditions used for the impregnation [52]. This image has been obtained by selecting a sheet of graphene in which nanoparticles of $S$ are sufficiently dispersed in order to favor a clear identification and evaluation of the particle size. In spite, a clear identification of the sulfur nanoparticles appears more difficult in some region of the grid in which a notable agglomeration occurs due to the high $\mathrm{S}$ content in the composite, as indeed indicated by TGA results. A similar behavior was observed by Chen et al. [52] using electron microscopy which revealed only isolated sulfur nanoparticles in a composite characterized by a loading as high as $80 \%$. The images also reveal signs of $\mathrm{S}$ crystallinity in the highly disordered carbon host matrix; this agrees with the XRD patterns (see Fig. S1(a) in the ESM). Diffuse fringes with thickness of ca. $3.8 \AA$ can be also observed in the TEM image (Fig. 5(c)), which is consistent with the spacing of (222) planes of sulfur. Furthermore, the blurring aspect of $S$ fringes suggests that $S$ nanoparticles are impregnated in the graphene network. EDX spectra were used to examine the element distribution in the composite (Fig. S6 in the ESM). The elemental mapping for the $\mathrm{S}, \mathrm{C}$, and $\mathrm{N}$ elements clearly reveals a homogeneous distribution. The CV curves of the composite in the potential range of $1.9-2.7 \mathrm{~V}$ at a scanning rate of $0.1 \mathrm{mV} \cdot \mathrm{s}^{-1}$ during the first three cycles are shown in Fig. 6(a). Two well-defined peaks observed at 2.37 and $2.03 \mathrm{~V}$ vs. $\mathrm{Li}^{+} / \mathrm{Li}$ during cathodic scan account for the $\mathrm{S}$ reduction, which occurs according to a multiple stage process [60], with formation of long-chain polysulphides $\left(\mathrm{Li}_{2} \mathrm{~S}_{x}, 6 \leq x \leq 8\right)$ and short-chain polysulphides $\left(\mathrm{Li}_{4} \mathrm{~S}_{2}, \mathrm{Li}_{2} \mathrm{~S}_{2}, \mathrm{Li}_{2} \mathrm{~S}\right)$. The subsequent anodic scan shows a wide peak at about $2.5 \mathrm{~V}$ vs. $\mathrm{Li}^{+} / \mathrm{Li}$ merging the oxidation processes of $\mathrm{Li}_{2} \mathrm{~S}$ and $\mathrm{Li}_{2} \mathrm{~S}_{2}$ into $\mathrm{Li}_{2} \mathrm{~S}_{8}$ and eventually $\mathrm{S}$ [61]. The modest 
changes of the voltammetry profiles during cycles suggest a relevant reversibility of the electrochemical reaction.

The lithium-ion diffusion coefficient $D_{\mathrm{Li}}$ of the cathode was calculated from $\mathrm{CV}$ measurements using the Randles-Sevcik equation [62]

$$
I_{\mathrm{p}}=2.69 \times 10^{5} n^{1 / 2} A D_{\mathrm{Li}}^{0.5} v^{0.5} C_{\mathrm{Li}}
$$

where $I_{\mathrm{p}}$ is the peak current, $n$ is the number of electron transfers in the reaction, $A$ is the electrode geometric area, $v$ the scanning rate, and $C_{\mathrm{Li}}$ the concentration of lithium ions in the electrolyte. Figure 6(b) shows the CV curves of the electrode measured under different scanning rates ranging from 0.1 to $1.0 \mathrm{mV} \cdot \mathrm{s}^{-1}$ between 1.8 and $2.8 \mathrm{~V}$. The relationship of $I_{\mathrm{p}}$ and $v^{0.5}$ is shown in Fig. 6(c). From the slope of these plots and Eq. (1), the $D_{\mathrm{Li}}$ values of the two cathodic peaks at $\sim 2.27 \mathrm{~V}\left(C_{1}\right)$ and $2.0 \mathrm{~V}\left(C_{2}\right)$ and the anodic peak at $\sim 2.40 \mathrm{~V}$ (A) were determined to be $5.7 \times 10^{-10}, 1.2 \times 10^{-9}$ and $1.9 \times$ $10^{-9} \mathrm{~cm}^{2} \cdot \mathrm{s}^{-1}$, respectively. These values are comparable with those calculated in literature for organosulphur compounds able to deliver high capacities on extended cycling [17].

Further insights in the electrochemical process were obtained from EIS measurements recorded at OCV and after four voltammetric cycles. The Nyquist plots (Fig. 6(d), and magnification in inset) intercept the real axis at high-frequency with value corresponding to the electrolyte resistance $\left(R_{\mathrm{e}}\right)$, and show semicircles in the mediumhigh frequency region related to the electrode/electrolyte interphase including resistances of both the charge transfer $\left(R_{\mathrm{ct}}\right)$ and the solid electrolyte interphase (SEI) film formed at the electrodes surface $[45,52,53]$. Sloping straight line in the lowfrequency region, known as the Warburg impedance, may be ascribed to the Li-ion diffusion within the electrode [13]. The results of the no-linear least squares (NLLSQ) analyses performed on the Nyquist plots of Fig. 6(d) are reported in Table 4 and Fig. S7 
in the ESM. The data indicate a remarkably low interphase resistance ( $R$ in Table 4$)$, which decreases from 27.8 to $21.9 \Omega$ upon $\mathrm{CV}$ due to a suitable reorganisation of the electrode material by cycling already observed in previous work [56, 64]. The low resistance values and the activation of the electrode by the ongoing of the process suggest facile charge carrier transport at the electrode/electrolyte interphase, and fast kinetics of the electrochemical reactions already observed by cyclic voltammetry of the A-3DNG/S composite in lithium cell.

The performance of the cell is studied under galvanostatic regime at different current rates, ranging from $\mathrm{C} / 10$ to $2 \mathrm{C}\left(1 \mathrm{C}=1,675 \mathrm{~mA} \cdot \mathrm{g}^{-1}\right)$. The steady-state charge/discharge curve at each rate is shown in Fig. 7(a). The two well-resolved plateaus of the discharge process are consistent with the two stages of the $\mathrm{S}$ reduction deduced from the $\mathrm{CV}$ curves. The figure reveals an average voltage above $2 \mathrm{~V}$, and a polarization increasing by raising the current rate due to the Ohmic drop and the kinetic limits already observed by $\mathrm{CV}$ at the higher scan rate. The corresponding trend of the capacity values during cycles is shown in Fig. 7(b) together with those of the S@3DNG for comparison. The average capacity values for the $\mathrm{S} @ \mathrm{~A}-3 \mathrm{DNG}$ vary from $1,350 \mathrm{mAh} \cdot \mathrm{g}^{-1}$ at $\mathrm{C} / 10$ to around $1,000 \mathrm{mAh} \cdot \mathrm{g}^{-1}$ at $2 \mathrm{C}$, this later a remarkably high value considering the elevated current rate. When the current rate is restored to $\mathrm{C} / 10$, the electrode recovers most of its capacity. It is worth noting that a composite without carbon activation retains similar capacity values at rates lower than $\mathrm{C} / 5$, while smaller capacity is delivered at higher crates in particular at $2 \mathrm{C}$ with a value barely reaching $800 \mathrm{mAh} \cdot \mathrm{g}^{-1}$. Furthermore, the activated composite retains higher capacity than non-activated when the current is lowered back to the pristine value of $\mathrm{C} / 10$ during the rate capability test. The evidence indicates that carbon activation process can actually improve the electrochemical performance of the sulfur composite in lithium cell. The electrode enhancement is most 
likely attributed to the increase of the micropore content and the resulting increase in the BET surface of the graphene nanoparticles promoted by the activation process. This good performance is also observed for long-term cycling tests carried out at 0.5 and $1 \mathrm{C}$ after being activated at $\mathrm{C} / 10$ for one cycle (Fig. 7(c)). At C/5 the Li-S cell exhibits an initial discharge capacity of $1,101 \mathrm{mAh} \cdot \mathrm{g}^{-1}$ and $860 \mathrm{mAh} \cdot \mathrm{g}^{-1}$ after 200 cycles with an average capacity of $977 \mathrm{mAh} \cdot \mathrm{g}^{-1}$; at $1 \mathrm{C}$ the cell delivers 824 and $737 \mathrm{mAh} \cdot \mathrm{g}^{-1}$ with an average capacity of $777 \mathrm{mAh} \cdot \mathrm{g}^{-1}$. In both cases, the Coulombic efficiency approached to $100 \%$ after the first few cycles. The lower capacity observed during the prolonged cycling (Fig. 7(c)) test with respect to the rate capability test (Fig. 7(c)) may be related to the different experimental conditions adopted for the two measurements, as well as to possible minor dissolution of the electrode during the initial stages of the test.

It is worth mentioning that the results found here on our N-doped graphene physically activated, are in line, and in some case even more enhanced, compared to some results reported in the literature as shown in Table 5. These results have been arranged in two sections to facilitate the comparison: The first section concerns various 3DN-doped graphenes, while the second one elucidates the effectiveness of physical activation compared to chemical activation. The S content taken into account is at least $60 \% \mathrm{w}: \mathrm{w}$, which is considered appropriate for possible scaling-up to battery scale. Regarding the electrode performance, a distinction is made between the prolonged cycling behaviour and the response of the electrode to changes in current densities (rate capability). For better comparison, the chosen data are those reported under equal or similar conditions to those used in this work, that is, $0.2 \mathrm{C}$ and $1 \mathrm{C}$ for long-cycle measurements, and $1 \mathrm{C}$ and $2 \mathrm{C}$ for rate capability test, which are the highest values studied.

Table 5 reveals that the results of the A-3DNG/S composite studied herein well compete with the best performances of other 3DN-doped graphene nanosheets. Indeed, long 
cycling tests reveal capacity values matching the best electrochemical responses, and even exceeding them when the cell is cycled at $1 \mathrm{C}$. This good behaviour is confirmed by the rate capability tests, with capacity values overcoming those shown in the first section of Table 5. Furthermore, the performance of our A-3DNG/S composite is comparable with that of new composites based on $\mathrm{N}$-doped graphene, prepared by Su et al. [40] using Prussian blue as $\mathrm{N}$ and $\mathrm{C}$ source. The latter complex system involves $\mathrm{Fe}_{3} \mathrm{C}$ and carbon nanotubes which is a particular composition leading to outstanding electrochemical behaviour, still to be achieved for our composite, such as very long life cycling (2,000 cycles) and remarkable rate capability (up to 10C).

The second section of Table 5, collecting sulfur composites based on chemically activated graphene both doped and undoped with $\mathrm{N}$, clearly shows that the presence of the element improves the electrochemical performance. Only the composite reported by Chen et al. [44] delivers higher capacity values than the one studied in this work during rate capability tests carried out under similar conditions, while the other composites deliver a lower capacity. The outstanding properties of the composite described by Chen et. al. can be ascribed to its suitable configuration obtained by a sophisticated procedure of the carbon matrix preparation involving GO, polypyrrole synthesized in situ as $\mathrm{N}$ source, $\mathrm{SiO}_{2}$ nanoparticles as the mesoporous guide, $\mathrm{HF}$ etching and $\mathrm{KOH}$ treatment. Although the comparison of the long cycling performances is more difficult due to the heterogeneity of the cycle number, the capacity value obtained in the rate capability tests in our compound is exceeded by the values found by Chen et al. [44], a difference which becomes smaller, i.e., 740 versus $860 \mathrm{mAh} \cdot \mathrm{g}^{-1}$, after 200 cycles at 1C. In summary, the results reported in our work well compete with the best performances reported in literature for chemically activated graphene. 
The A-3DNG/S electrode is further investigated by SEM before and after cycling in sulphur cell (Fig. S8 in the ESM). The SEM image before cycling (Fig. S8(a) in the ESM) shows the macroporous texture of the deposit, which is well adapted for an effective impregnation by the electrolyte. After cycling (Fig. S8(b) in the ESM), the deposit becomes more compact and the contact between the particles seems improved, thus accounting for the structural retention and the negligible deterioration of the electrode during cycling, which is indeed demonstrated by the absence of holes of zones in which the active material is detached after cell dismantling.

Different factors could explain the good performance of the A-3DGN/S composite. The first factor is the formation of a 3D interconnected network of micro-, meso- and macropores, which results from a combination of the synthesis procedure aimed to exfoliate the GO layers and the sheet self-assembly in a 3D framework followed by physical activation with $\mathrm{CO}_{2}$ to induce the micropore system. These voids can store the S particles and trap the polysulphides originated during the electrochemical reaction. The adsorption properties of the A-3DNG matrix towards polysulphides (mainly $\mathrm{Li}_{2} \mathrm{~S}_{4}$ ), prepared according to the previously reported Ref. [65], are shown in Fig. S9 in the ESM. For comparison, the behaviour of 3DG and 3DNG matrixes have also been included. After absorption for $18 \mathrm{~h}$, the colour of the polysulfide solution changes from orange to yellow with the addition of the 3DG and 3DNG samples. On the other hand, the solution becomes apparently colourless when the sample A-3DNG is added. The sequence of the absorption power of the samples is better evaluated by examining their UV/vis spectra reported in Fig. S9 in the ESM. The solution shows a more intense peak at ca. $460 \mathrm{~nm}$ and a weaker one at ca. $420 \mathrm{~nm}$, suggesting the presence of polysulfides of various lengths. The addition of the carbon samples decreases the intensity of the major peak, however less remarkably for the 3DG sample. Furthermore, the peak at 420 
$\mathrm{nm}$, responsible for the yellow colour, is barely perceptible when the A-3DNG is added. The sequence in the absorption powers (i.e., A-3DNG > 3DNG > 3DG) well confirms the beneficial effect of the activation process in improving the polysulfide retention property of the studied carbon matrix.

The second aspect is the presence of $\mathrm{N}$ in the graphene structure, which is the more commonly analysed doping element. This element is beneficial for enhancing both the conductivity and the polysulphide adsorption properties of pure graphene. The improvement in the conductivity is attributed to the graphitic nitrogen state [51], and the adsorption properties from the pyridinic and pyrrolic nitrogen states [52] as deduced from the $\mathrm{N}$ 1s photoemission peak. According to Table 3, the percentages of the three $\mathrm{N}$ states are significant and hence serve as evidence that both properties can improve. The third factor to be considered is the nanometric size of S particles, which is below $10 \mathrm{~nm}$ as revealed from high-resolution (HRTEM) images. The nanometric particle size would increase the rate of the electrochemical reaction between $\mathrm{S}$ and $\mathrm{Li}$, thus contributing to the good behaviour of the electrode at high current densities.

\section{Conclusions}

A hierarchically micro- meso- macroporous 3D-graphene doped with $\mathrm{N}$ has been successfully prepared through a solvothermal microwave treatment of GO together with urea as the $\mathrm{N}$ source, and activated with $\mathrm{CO}_{2}$ to generate a micropore texture. Sulphur dissolved in ethylenediamine was then confined into the graphene framework as monodispersed nanoparticle; moreover, the method yielded a homogeneous distribution of the sulphur in the composite. Used as the cathode in Li-S batteries, the A-3DNG/S composite displayed a high specific capacity, good rate capability, and cycling stability. This outstanding performance has been ascribed to a 3D porous structure able to trap 
polysulphide, hindering their diffusion in the electrolyte and mitigating the shuttle effect as a result. Physical activation methods are simple, clean, and fast, in particular if compared to chemical activation methods, and apparently lead to even better performance in Li/S battery. Therefore, the synthetic procedure adopted herein for the A-3DNG/S preparation is proposed as very suitable route to obtain alternative electrodes for high-performance Li-S batteries.

\section{Acknowledgements}

This work was performed with the financial support of the Ministerio de Economía y Competitividad (No. MAT2017-87541-R) and Junta de Andalucía (Group FQM-175). J.

H. thanks the University of Ferrara for the grant "Fondo di Ateneo per la Ricerca Locale (FAR) 2017”.

Electronic Supplementary Material: Supplementary material

( ) is available in the online version of this article at https://doi.org/10.1007/s12274-0192285-z. 
Figure 1 Scheme of the preparation of the $3 \mathrm{D}$ graphene activated with $\mathrm{CO}_{2}$.

Figure 2 XPS spectra of A-3DNG (a) C1s; (b) N1s.

Figure $3 \mathrm{~N}_{2}$ adsorption/desorption isotherms of A-3DNG. $\mathrm{N}_{2}$ adsorption/desorption isotherms of $\mathrm{A}-3 \mathrm{DNG} / \mathrm{S}$ is included in the inset.

Figure 4 SEM (a) and TEM (b) images of A-3DNG.

Figure 5 TEM images of A-3DNG/S composite obtained at different magnifications. 
Figure $6 \mathrm{CV}$ curves (a), the scan rate-dependent CV (b), the corresponding variation of the peak current with the square root of the scan rate (c), and the EIS spectra (d) of the A-3DNG/S composite.

Figure 7 First galvanostatic discharge-charge curve at different rates (a), rate performance (b), and cycling performance (c) of the cell made from the A-3DNG/S composite. The rate performance of the $3 \mathrm{DNG} / \mathrm{S}$ composite has been included for comparison.

Table 1 Atomic concentration of C, O, N (in \%) obtained from XPS analysis

\begin{tabular}{|c|c|c|c|c|}
\hline Sample & $\mathrm{C}$ & $\mathrm{O}$ & $\mathrm{N}$ & C/O ratio \\
\hline A-3DNG & 91.18 & 5.52 & 3.30 & 16.51 \\
\hline
\end{tabular}

Table 2 Contribution of the six components used in the fitting of the $\mathrm{C} 1 \mathrm{~s}$ core level signal (in \%) and $\mathrm{BE}$ in $\mathrm{eV}$ 


\begin{tabular}{|l|c|c|c|c|c|c|}
\hline \multirow{2}{*}{$\mathrm{BE}(\mathrm{eV})$} & $\begin{array}{c}\mathrm{C}=\mathrm{C} / \mathrm{C}- \\
\mathrm{C}-\end{array}$ & $\mathrm{C}-\mathrm{N}$ & $\mathrm{C}-\mathrm{O}$ & $\mathrm{C}=\mathrm{O}$ & $\mathrm{O}-\mathrm{C}=\mathrm{O}$ & $\pi \rightarrow \pi *$ \\
& 284.8 & 285.9 & 286.7 & 288.0 & 289.0 & 290.8 \\
& & & & & & \\
\hline A-3DNG & 69.00 & 17.14 & 6.43 & 2.76 & 1.88 & 2.80 \\
\hline
\end{tabular}

Table 3 Contribution of the three components used in the fitting of the $\mathrm{N} 1 \mathrm{~s}$ photoemission peak (in \%). $\mathrm{BE}$ in $\mathrm{eV}$

\begin{tabular}{|c|c|c|c|}
\hline BE $(\mathrm{eV})$ & $\begin{array}{c}\text { Pyridinic N } \\
398.7\end{array}$ & $\begin{array}{c}\text { Pyrrolic N } \\
400.0\end{array}$ & $\begin{array}{c}\text { Graphitic N } \\
\end{array}$ \\
\hline A-3DNG & 44.54 & 28.44 & 26.0 \\
\hline
\end{tabular}

Table 4 NLLSQ analyses performed on the impedance spectra of Fig. 6(d), recorded upon cyclic voltammetry A-3DNG/S composite in lithium cell

\begin{tabular}{|l|l|l|l|l|l|l|}
\hline $\begin{array}{l}\text { Cell } \\
\text { condition }\end{array}$ & Circuit & $\begin{array}{l}\boldsymbol{R}_{\mathbf{1}} \\
(\mathbf{\Omega})\end{array}$ & $\begin{array}{l}\boldsymbol{R}_{\mathbf{2}} \\
(\mathbf{\Omega})\end{array}$ & $\begin{array}{l}\boldsymbol{R}_{\mathbf{3}} \\
(\mathbf{\Omega})\end{array}$ & $\begin{array}{l}\boldsymbol{R}_{\mathbf{2}}+\boldsymbol{R}_{\mathbf{2}}+ \\
\boldsymbol{R}_{\mathbf{3}} \\
(\boldsymbol{\Omega})\end{array}$ & $\chi^{\mathbf{2}}$ \\
\hline OCV & $R_{\mathrm{e}}\left(R_{\mathrm{i}, 1} Q_{\mathrm{i}, 1}\right)\left(R_{\mathrm{i}, 2} Q_{\mathrm{i}, 2}\right) Q_{\mathrm{g}}$ & $\begin{array}{l}25.3 \pm \\
0.2\end{array}$ & $2.5 \pm 0.9$ & - & $27.8 \pm 0.9$ & $\begin{array}{l}6.6 \times \\
10^{-5}\end{array}$ \\
\hline After CV & $\begin{array}{l}R_{\mathrm{e}}\left(R_{\mathrm{i}, 1} Q_{\mathrm{i}, 1}\right)\left(R_{\mathrm{i}, 2} Q_{\mathrm{i}, 2}\right) \\
\left(R_{\mathrm{i}, 3} Q_{\mathrm{i}, 3}\right) Q_{\mathrm{g}}\end{array}$ & $3.0 \pm 0.8$ & $\begin{array}{l}10.1 \pm \\
0.3\end{array}$ & $8.8 \pm 3.2$ & $21.9 \pm 2.3$ & $4.8 \times$ \\
& & 0.3 & & $10^{-5}$ \\
\hline
\end{tabular}

Table 5 Selected properties of Li/S cells made from $\mathrm{N}$-doped graphenes and chemically activated graphenes reported in literature. The properties of our physically activated graphene are also included for comparison

\begin{tabular}{|c|c|c|c|c|c|c|c|}
\hline \multirow[b]{2}{*}{$\begin{array}{c}\text { Preparation method } \\
\text { (graphene source: GO) }\end{array}$} & \multirow[b]{2}{*}{$\begin{array}{c}\boldsymbol{S} \\
\text { (wt.\%) }\end{array}$} & \multicolumn{3}{|c|}{ Long cycling } & \multicolumn{2}{|c|}{ Rate Cap. } & \multirow[b]{2}{*}{ Ref. } \\
\hline & & $\begin{array}{r}\text { Rate } \\
\text { 200ccules } \\
\text { (C) }\end{array}$ & $C_{\text {initial }}$ & $\begin{array}{c}C \\
\left(A h \cdot g_{s}^{-1}\right)\end{array}$ & $\begin{array}{r}\text { Rate } \\
{ }_{1}(\mathrm{C})\end{array}$ & $\begin{array}{l}\text { pacity } \\
\text { nAh } g_{s}^{-}\end{array}$ & \\
\hline \multicolumn{8}{|c|}{ N-DOPED GRAPHENE NANOSHEETS } \\
\hline $\begin{array}{l}\text { Hydrothermal reduction at } 180{ }^{\circ} \mathrm{C}(12 \mathrm{~h}) \text {. } \\
\text { Calcined at } 900^{\circ} \mathrm{C}(2 \mathrm{~h}) . \mathrm{N} \text { source: } \mathrm{NH}_{3} \text {. } \\
850^{\circ} \mathrm{C}(4 \mathrm{~h})\end{array}$ & 80 & 0.2 & 1,042 & 920 & $\begin{array}{l}1 \\
2\end{array}$ & $\begin{array}{l}752 \\
538\end{array}$ & [30] \\
\hline
\end{tabular}




\begin{tabular}{|c|c|c|c|c|c|c|c|}
\hline $\begin{array}{l}\text { Hydrothermal reduction at } 180{ }^{\circ} \mathrm{C}(12 \mathrm{~h}) . \mathrm{N} \\
\text { source: } \mathrm{NH}_{3} \text { solution }\end{array}$ & 59 & 0.2 & 1,059 & 470 & $\begin{array}{l}1 \\
2\end{array}$ & $\begin{array}{l}580 \\
517\end{array}$ & [31] \\
\hline $\begin{array}{l}\text { Refluxed at } 90{ }^{\circ} \mathrm{C} . \text { Heated at } 800{ }^{\circ} \mathrm{C} . \mathrm{N} \\
\text { source: melamine resin }\end{array}$ & 54 & 0.25 & $1,130^{*}$ & 880 & $\begin{array}{l}1 \\
2\end{array}$ & $\begin{array}{l}750 \\
700\end{array}$ & [32] \\
\hline $\begin{array}{l}\text { Calcined at } 400{ }^{\circ} \mathrm{C}(2 \mathrm{~h}) . \mathrm{N} \text { source: } \mathrm{NH}_{3} \text { gas } \\
\text { flow }\end{array}$ & 68 & 0.18 & 1,200 & $880^{+}$ & $\begin{array}{l}0.9 \\
1.8\end{array}$ & $\begin{array}{l}770 \\
550\end{array}$ & [33] \\
\hline Calcined at $800{ }^{\circ} \mathrm{C}(2 \mathrm{~h}) . \mathrm{N}$ source: $\mathrm{Py}^{\mathrm{a}}$ & 76 & 0.2 & 1,200 & $926^{+}$ & $\begin{array}{l}1 \\
2\end{array}$ & $\begin{array}{l}860 \\
730\end{array}$ & [34] \\
\hline $\begin{array}{l}\text { Calcined at } 900 \quad{ }^{\circ} \mathrm{C} \\
\text { dicyandiamide }\end{array}$ & 66 & 0.5 & 1,344 & 552 & $\begin{array}{l}1 \\
2\end{array}$ & $\begin{array}{l}600 \\
500\end{array}$ & [35] \\
\hline $\begin{array}{l}\text { Calcined at } 750{ }^{\circ} \mathrm{C}(1 / 2 \mathrm{~h}) . \mathrm{N} \text { source: } \mathrm{NH}_{3} \\
\text { gas flow }\end{array}$ & 60 & 0.2 & 900 & $680^{+++}$ & $\begin{array}{l}1 \\
2\end{array}$ & $\begin{array}{l}910 \\
720\end{array}$ & [36] \\
\hline $\begin{array}{l}\text { Calcined at } 750 \quad{ }^{\circ} \mathrm{C} \\
\text { ethylendiamine }\end{array}$ & 60 & 1 & 610 & 600 & $\begin{array}{l}1 \\
2\end{array}$ & $\begin{array}{l}650 \\
590\end{array}$ & [37] \\
\hline $\begin{array}{l}\text { Hydrothermal reduction at } 180{ }^{\circ} \mathrm{C}(12 \mathrm{~h}) . \mathrm{N} \\
\text { source: urea }\end{array}$ & 80 & $\begin{array}{c}0.1 \\
1\end{array}$ & $\begin{array}{c}1,268 \\
100\end{array}$ & $\begin{array}{l}764 \\
650\end{array}$ & 1 & 630 & [38] \\
\hline $\begin{array}{l}\text { Hydrothermal reduction at } 200{ }^{\circ} \mathrm{C}(12 \mathrm{~h}) . \mathrm{N} \\
\text { source: } \mathrm{NH}_{3} \text { solution }\end{array}$ & 86 & 0.9 & 800 & 680 & 0.9 & 785 & [39] \\
\hline $\begin{array}{l}\text { Calcined at } 900{ }^{\circ} \mathrm{C}(3 \mathrm{~h}) . \mathrm{N} \text { and graphene } \\
\text { source: } \mathrm{Na}_{4} \mathrm{Fe}(\mathrm{CN})_{6} \rightarrow \mathrm{Fe}_{3} \mathrm{C} @ / \mathrm{N}-\mathrm{G} / \mathrm{CNT} \\
\text { hybrid composite }\end{array}$ & 70 & 1 & 850 & 720 & 2 & 700 & [40] \\
\hline \multicolumn{8}{|c|}{ GRAPHENE ACTIVATED BY CHEMICAL METHODS } \\
\hline $\begin{array}{l}\text { Hydrothermal reduction of } \mathrm{GO} \text { at } 180^{\circ} \mathrm{C}(2 \\
\text { h). Activated with } \mathrm{KOH} \text { at } 900^{\circ} \mathrm{C}(1 \mathrm{~h})\end{array}$ & 68 & 0.5 & 900 & $640^{+}$ & $\begin{array}{l}1 \\
2\end{array}$ & $\begin{array}{l}740 \\
660\end{array}$ & [43] \\
\hline $\begin{array}{l}\mathrm{GO} \text { treated with } \mathrm{SiO}_{2} \text {, Py and APS; heated } \\
\text { at } 850^{\circ} \mathrm{C}(2 \mathrm{~h}) \text {. Activated with } \mathrm{KOH} \text { at } 800 \\
{ }^{\circ} \mathrm{C}(2 \mathrm{~h})(\mathrm{N}-\text { and S-doped? })\end{array}$ & 74 & 1 & 1,400 & $860^{+}$ & $\begin{array}{l}1 \\
2\end{array}$ & $\begin{array}{l}1,200 \\
1,100\end{array}$ & [44] \\
\hline $\begin{array}{l}\text { Microwave exfoliated GO activated with } \\
\mathrm{KOH} \text { at } 400^{\circ} \mathrm{C}(2 \mathrm{~h})\end{array}$ & 81 & $\begin{array}{c}0.15 \\
1\end{array}$ & $\begin{array}{c}1,200 \\
600\end{array}$ & $\begin{array}{c}670^{+} \\
533\end{array}$ & 1 & 587 & [45] \\
\hline $\begin{array}{l}\text { GO treated with } \mathrm{CTAB}^{\mathrm{b}} \text {, } \mathrm{APS}^{\mathrm{c}} \text { and } \mathrm{Py}^{\mathrm{d}} \text {. } \\
\text { Activated with } \mathrm{K}_{2} \mathrm{CO}_{3} \text { at } 800{ }^{\circ} \mathrm{C}(2 \mathrm{~h})(\mathrm{N}- \\
\text { and S-doped) }\end{array}$ & 72 & 0.2 & 1,178 & 780 & $\begin{array}{l}1 \\
2\end{array}$ & $\begin{array}{l}980 \\
800\end{array}$ & [46] \\
\hline $\begin{array}{l}\text { Hydrothermal reduction of } \mathrm{GO} \text { at } 150{ }^{\circ} \mathrm{C} \\
(10 \mathrm{~h}) \text {. Activated with } \mathrm{KOH} \text { at } 800^{\circ} \mathrm{C}(1 \mathrm{~h})\end{array}$ & 67 & 1 & 927 & $685^{+}$ & - & - & [47] \\
\hline $\begin{array}{l}\text { Chemical reduction of GO by hydrazine and } \\
\text { functionalized with PAN }{ }^{\mathrm{d}} \text {. Activated with } \\
\mathrm{ZnCl}_{2} \text { (N-doped) }\end{array}$ & 72 & 1.2 & 1,150 & $700^{++}$ & $\begin{array}{l}0.9 \\
1.8\end{array}$ & $\begin{array}{l}920 \\
800\end{array}$ & [48] \\
\hline $\mathrm{N}$-doped graphene activated with $\mathrm{CO}_{2}$ & 70 & $\begin{array}{c}0.2 \\
1\end{array}$ & $\begin{array}{c}1,101 \\
772\end{array}$ & $\begin{array}{l}870 \\
740\end{array}$ & $\begin{array}{l}1 \\
2\end{array}$ & $\begin{array}{l}1,081 \\
1,000\end{array}$ & $\begin{array}{l}\text { This } \\
\text { work }\end{array}$ \\
\hline
\end{tabular}

${ }^{+} 100 ;{ }^{++} 120 ;{ }^{+++160}$ cycles. aPy: pyrrole. ${ }^{b}$ CTAB: cetyltrimethylammonium bromide. ${ }^{c}$ APS: ammonium persulfate. dPAN: polyacrylonitrile.

TOC 